\title{
Gambaran Waktu Tunggu Operasi Hip Replacement pada Pasien Manula dengan Patah Tulang Pinggul Periode November 2017-Desember 2018 di RSUP Prof. Dr. R. D. Kandou Manado
}

\author{
Tio G. L. Thadius, ${ }^{1}$ Andriessanto C. Lengkong, ${ }^{2}$ Angelica M. J. Wagiu ${ }^{2}$
}

\author{
${ }^{1}$ Program Studi Pendidikan Dokter Fakultas Kedokteran Universitas Sam Ratulangi Manado \\ ${ }^{2}$ Bagian Ilmu Bedah Fakultas Kedokteran Universitas Sam Ratulangi-RSUP Prof. Dr. R. D. \\ Kandou Manado \\ Email: tgraciniyo@gmail.com
}

\begin{abstract}
Hip fracture often occurs over the age of 60 years and is more common in women due to postmenopausal osteoporosis. Timing of surgery is thought to play an important role regarding survival. Moreover, international clinical practice guidelines recommend surgical treatment of acute hip fracture within 24 to 48 hours after admission. Some researchers argue that early surgery can lead to an increased the risk of perioperative complications. This study was aimed to determine the incidence of hip fracture, the impact of timing of surgery on perioperative complications, and the mortality in elderly patients with hip fracture from November 2017 to December 2018 at Prof. Dr. R. .D. Kandou Hospital Manado. This was a retrospective and descriptive study using data of patient medical record. The results found 32 cases of hip fractures, and the highest incidence was in females. Most patients did not have any perioperative complications as many as 26 cases. Moreover, there was no patients who died due to the impact of timing of surgery. In conclusion, most hip fracture cases were female. There was a relationship between delayed time in surgery and perioperative complications, however, there was no relationship between delayed time in surgery and patient mortality.
\end{abstract}

Keywords: hip fracture, delay time of surgery, complication, mortality

\begin{abstract}
Abstrak: Patah tulang pinggul sering terjadi pada usia di atas 60 tahun dan lebih sering pada perempuan yang disebabkan oleh kerapuhan tulang akibat kombinasi proses penuaan dan osteoporosis pascamenopause. Waktu tunggu operasi dianggap memiliki peran yang penting dalam kelangsungan hidup. Pedoman praktik klinis internasional merekomendasikan perawatan bedah patah tulang pinggul akut dalam waktu 24 hingga 48 jam setelah cedera namun beberapa peneliti berpendapat bahwa operasi dini dapat menyebabkan peningkatan resiko komplikasi perioperatif. Penelitian ini bertujuan untuk mengetahui angka kejadian patah tulang pinggul serta dampak waktu tunggu operasi terhadap komplikasi perioperatif dan risiko kematian pada pasien manula dengan patah tulang pinggul periode November 2017-Desember 2018 di RSUP Prof. Dr. R. D. Kandou Manado. Jenis penelitian ialah deskriptif retrospektif menggunakan data rekam medik pasien. Hasil penelitian mendapatkan 32 kasus patah tulang pinggul, dengan angka kejadian terbanyak pada perempuan. Jumlah pasien dengan komplikasi sebanyak 6 kasus dan pasien tanpa komplikasi sebanyak 26 kasus. Tidak ditemukan adanya pasien yang meninggal oleh karena lama waktu tunggu operasi. Simpulan penelitian ini ialah sebagian besar kejadian patah tulang pinggul terjadi pada perempuan, dan terdapat hubungan antara waktu tunggu operasi dengan peningkatan komplikasi perioperatif, namun tidak terdapat hubungan antara waktu tunggu operasi terhadap peningkatan angka mortalitas pasien.
\end{abstract}

Kata kunci: patah tulang pinggul, waktu tunggu operasi 


\section{PENDAHULUAN}

Patah tulang pinggul sering terjadi pada usia di atas 60 tahun dan lebih sering pada perempuan yang disebabkan oleh kerapuhan tulang akibat kombinasi proses penuaan dan osteoporosis pasca menopause. $^{1,2}$

Patah tulang pinggul pada populasi manula merupakan masalah kesehatan utama di Eropa dan Amerika Serikat. ${ }^{3-5}$ Insiden patah tulang pinggul tahunan meningkat seiring bertambahnya usia. Di Amerika Serikat, insiden patah tulang pinggul berkisar antara $0,2 \%$ pada perempuan berusia 60 hingga 64 tahun, hingga $2,5 \%$ pada perempuan berusia 85 tahun atau lebih tua. ${ }^{6}$ Di Eropa, insiden patah tulang pinggul tahunan untuk perempuan lanjut usia berusia 60 tahun atau lebih berkisar antara $0,5 \%$ hingga $1,6 \%$ per tahun. ${ }^{7-9}$ Angka kejadian patah tulang pinggul dapat ditemukan di berbagai negara di Asia seperti Singapura, Taiwan, Jepang, Malaysia, dan Cina, tetapi angka kejadian belum tercatat di negara Indo-nesia. Untuk angka kejadian di Kota Manado sendiri, tepatnya di RSUP Prof. Dr. R. D. Kandou Manado tahun 2017-2018 insiden patah tulang pinggul pada pasien manula berusia 65 tahun ke atas terdapat 32 kasus. Risiko untuk laki-laki setengah dari presentasi jumlah perem-puan. ${ }^{10}$

Patah tulang pinggul pada pasien manula merupakan cedera serius yang dapat menyebabkan imobilitas dan ketergantungan permanen, serta berdampak negatif pada kualitas hidup pasien dan mengakibatkan beban finansial pada sistem kesehatan dan sosial. ${ }^{9-12}$ Patah tulang pinggul juga dapat menyebabkan kematian. Tingkat kematian pada pasien manula yang mengalami patah tulang pinggul berkisar antara 14\%-36\% dalam setahun setelah cedera. ${ }^{13-21}$ Selama tiga bulan pertama setelah patah tulang pinggul, pasien lanjut usia memiliki risiko sekarat yang meningkat lima hingga delapan kali lipat. ${ }^{22}$ Peningkatan risiko kematian berlanjut hingga sepuluh tahun. ${ }^{22}$ Karena perkiraan peningkatan harapan hidup di negaranegara Barat selama beberapa dekade mendatang, ${ }^{23-25}$ patah tulang pinggul dan konsekuensinya akan memiliki dampak yang lebih besar pada sistem kesehatan dan masyarakat di masa depan.

Faktor-faktor yang memengaruhi prognosis pasien manula setelah patah tulang pinggul ialah usia, jenis kelamin, komorbiditas, dan status kesehatan fisik umum pada saat cedera. ${ }^{26}$ Selain itu, waktu tunggu operasi dianggap memiliki peran yang penting dalam kelangsungan hidup. Meskipun pedoman praktik klinis internasional merekomendasikan perawatan bedah fraktur pinggul akut dalam waktu 24 hingga 48 jam setelah cedera, ${ }^{27-29}$ rekomendasi ini masih dibahas secara kontroversial. ${ }^{30-32}$ Beberapa peneliti berpendapat bahwa operasi dini dapat menyebabkan peningkatan resiko komplikasi perioperatif, termasuk pneumonia, trombosis vena dalam, perdarahan, emboli paru, infeksi saluran kemih, dan ulserasi dekubital karena dokter tidak memiliki cukup waktu untuk mengoptimalkan kondisi medis pasien sebelum operasi. $^{31-33}$

Untuk memberikan gambaran komprehensif, perlu untuk meninjau secara sistematis bukti yang tersedia saat ini tentang dampak waktu tunggu operasi pada pasien manula dengan patah tulang pinggul akut. Penelitian ini bertujuan untuk menilai hasil terkait pasien lainnya, seperti angka kejadian, komplikasi pasca operasi, dan risiko kematian.

\section{METODE PENELITIAN}

Penelitian ini dilakukan terhadap pasien manula dengan patah tulang pinggul di RSUP Prof. Dr. R. D. Kandou Manado. Jenis penelitian ialah deskriptif dengan pendekatan retrospektif menggunakan data rekam medik pasien dalam periode waktu tertentu dan mengolahnya kembali. Sampel penelitian ialah pasien manula dengan patah tulang pinggul periode November 2017-Desember 2018 yang memenuhi kriteria inklusi. Variabel penelitian ini yaitu jumlah insiden patah tulang pinggul, usia, jenis kelamin, operasi hip replacement, komplikasi pasca operasi, dan angka kematian. 
Penelitian ini telah mendapat persetujuan dari Komisi Etik Penelitian Kesehatan RSUP Prof. Dr. R. D. Kandou Manado, dengan nomor keterangan layak etik yaitu No. 075/EC/KEPK-KANDOU/XI/2019.

\section{HASIL PENELITIAN}

Jumlah tindakan operasi hip replacement di RSUP Prof. Dr. R. D. Kandou Manado periode November 2017-Desember 2018 ialah sebanyak 49 tindakan, namun hanya 32 sampel saja yang dapat diteliti dikarenakan 17 sampel yang lain tidak memenuhi kriteria inklusi penelitian serta tidak memiliki data rekam medik yang lengkap.

Hasil penelitian mendapatkan dari 32 sampel, 30 pasien menjalani operasi total hip replacement sedangkan 2 pasien menjalani operasi partial hip replacement. Berdasarkan jenis kelamin didapatkan insiden patah tulang pinggul pada laki-laki sebanyak 9 pasien dan pada perempuan sebanyak 23 pasien.

Tabel 1 memperlihatkan jumlah insiden patah tulang pinggul berdasarkan lama waktu tunggu operasi dan yang terbanyak ialah waktu tunggu 1-2 bulan yaitu 17 pasien.

Tabel 2 memperlihatkan kejadian komplikasi pasca operasi, yang terbanyak ialah tanpa komplikasi, baik pada 1-7 hari, 7-30 hari, 1-2 bulan, dan $>2$ bulan. Selama periode November 2017-Desember 2018, tidak didapatkan pasien manula pasca operasi hip replacement yang meninggal.

\section{BAHASAN}

Dari hasil penelitian dapat disimpulkan bahwa jumlah kasus patah tulang pinggul pada pasien manula di RSUP Prof. Dr. R. D. Kandou Manado selama periode November 2017-Desember 2018 bersifat fluktuatif dan tidak membentuk suatu pola khusus. Jumlah kasus patah tulang pinggul pada pasien manula di RSUP Prof. Dr. R. D. Kandou Manado periode November 2017-Desember 2018 sebanyak 49 pasien, tetapi yang diikutkan dalam penelitian ini berjumlah 32 pasien. Berdasarkan jenis tindakan operasi, yang terbanyak ialah total hip replacement.

Pada penelitian ini didapatkan jumlah pasien patah tulang pinggul jauh lebih banyak pada jenis kelamin perempuan dibandingkan laki-laki (23 vs 9 pasien). Hal ini sejalan dengan penelitian yang dilakukan oleh Kanis et $\mathrm{al}^{10}$ yang menyatakan bahwa jumlah insiden patah tulang pinggul di beberapa negara di dunia menunjukkan angka insiden pada perempuan dua kali lipat lebih tinggi dari jumlah insiden pada laki-laki. Hal ini disebabkan oleh kerapuhan tulang akibat kombinasi proses penuaan dan osteoporosis pascamenopause. ${ }^{1}$ Osteoporosis pascamenopause terjadi karena kurangnya hormon estrogen pada perempuan yang berusia antara 51-75 tahun, tetapi dapat muncul lebih cepat atau lebih lambat. ${ }^{34}$ Kepadatan tulang juga dipengaruhi oleh asupan kalsium. Hasil penelitian Kosnayani $^{35}$ menunjukkan kepadatan tulang pasca menopause sebesar $84,77 \%$ disebabkan oleh kurangnya asupan kalsium.

Tabel 1. Jumlah insiden patah tulang pinggul pada pasien manula berdasarkan lama waktu tunggu operasi

\begin{tabular}{ccccc}
\hline $\begin{array}{c}\text { Lama waktu } \\
\text { tunggu }\end{array}$ & $\mathbf{1 - 7}$ hari & $\mathbf{7 - 3 0}$ hari & $\mathbf{1 - 2}$ bulan & $>\mathbf{2}$ bulan \\
Jumlah pasien & 1 & 10 & 17 & 4 \\
\hline
\end{tabular}

Tabel 2. Gambaran waktu tunggu operasi terhadap komplikasi pasca operasi

\begin{tabular}{ccccc}
\hline & $\mathbf{1 - 7}$ hari & $\mathbf{7 - 3 0}$ hari & $\mathbf{1 - 2}$ bulan & $>$ 2 bulan \\
Hematoma & 0 & 1 & 2 & 1 \\
Dislokasi & 0 & 1 & 0 & 1 \\
Tanpa komplikasi & 1 & 8 & 14 & 3 \\
\hline
\end{tabular}


Nurwahyuni dan Wirawanni ${ }^{36}$ melakukan uji korelasi antara asupan kalsium dengan kepadatan tulang pasca menopause dan menunjukkan adanya hubungan yang positif dan bermakna. Status sosio-ekonomi juga merupakan salah satu faktor risiko osteoporosis. Hasil penelitian Fatmah $^{37}$ menyatakan persentase osteoporosis pada responden berpendidikan rendah lebih besar dibandingkan yang berpendidikan tinggi. Individu dengan tingkat pendidikan tinggi cenderung mempunyai pengetahuan dan perilaku/gaya hidup kesehatan lebih baik dan konsumsi makanan sumber kalsium.

Lama waktu tunggu didapatkan dari selisih antara waktu insiden dan waktu tindakan operasi. Parameter waktu tunggu operasi yang digunakan ialah 1-7 hari, >730 hari, 1-2 bulan, dan $>2$ bulan. Berbeda dengan penelitian-penelitian sebelumnya yang menggunakan parameter 12 jam, 24 jam, 48 jam, dan 72 jam, pada penelitian ini peneliti memodifikasi parameter waktu tunggu operasi dikarenakan tidak pernah ada tindakan operasi hip replacement secara dini yang dilakukan di RSUP Prof. Dr. R. D. Kandou Manado. Hasil penelitin ini mendapatkan jumlah insiden patah tulang pinggul dengan lama waktu tunggu 1-7 hari sebanyak 1 kasus; lama waktu tunggu 7-30 hari sebanyak 10 kasus; lama waktu tunggu 1-2 bulan sebanyak 17 kasus; dan lama waktu tunggu $>2$ bulan sebanyak 4 kasus. Dengan demikian dapat disimpulkan bahwa jumlah insiden patah tulang pinggul pada pasien manula di RSUP Prof. Dr. R. D. Kandou Manado periode November 2017-Desember 2018 berdasarkan lama waktu tunggu operasi terbanyak ialah pada 1-2 bulan waktu tunggu operasi.

Dari 32 sampel yang diteliti, setengah diantaranya memilih pengobatan tradisional terlebih dahulu setelah cedera seperti tukang pijat dibandingkan dengan perwatan medis di rumah sakit. Hal ini menunjukkan bahwa masih kurangnya edukasi terhadap masyarakat mengenai pertolongan pertama pasca trauma secara khusus terhadap lansia. Disamping itu proses administrasi pasien dengan asuransi kesehatan juga dinilai berpengaruh terhadap lama waktu tunggu operasi. Hal ini mencakup proses menunggu alat dan sistem rujukan dari fasilitas kesehatan pertama ke fasilitas kesehatan lanjut yang dapat menambah lama waktu tunggu operasi pasien.

Data komplikasi pasca operasi dari pasien didapat berdasarkan catatan tinjauan pasca tindakan operasi dalam rekam medik pasien. Jumlah pasien dengan komplikasi sebanyak 6 kasus dan tanpa komplikasi sebanyak 26 kasus. Jumlah komplikasi terbanyak ialah hematoma sebanyak 4 kasus, dengan rincian 1 kasus pada waktu tunggu operasi 7-30 hari; 2 kasus pada waktu tunggu 1-2 bulan; dan 1 kasus pada waktu tunggu $>2$ bulan. Jumlah komplikasi dislokasi sebanyak 2 kasus dengan rincian, 1 kasus pada waktu tunggu 7-30 hari, dan 1 kasus pada waktu tunggu $>2$ bulan. Hasil penelitian ini tidak dapat dibandingkan dengan temuan-temuan penelitian yang ada. Hal ini disebabkan karena beberapa studi yang melakukan penelitian dampak waktu tunggu operasi terhadap komplikasi pasca operasi pada kasus patah tulang pinggul pasien manula menggunakan parameter waktu tunggu 12 jam, 24 jam, 48 jam, dan 72 jam, sedangkan semua tindakan operasi hip replacement di RSUP Prof. Dr. R. D. Kandou Manado dilakukan dengan kisaran rentang waktu 5 hari hingga 1 tahun setelah cedera. Dengan demikian dapat disimppulkan bahwa tindakan operasi dini pada pasien manula dengan patah tulang pinggul periode November 2017Desember 2018 di RSUP Prof. Dr. R. D. Kandou Manado tidak pernah dilakukan.

Penilaian jumlah angka kematian pada pasien manula dengan patah tulang pinggul di RSUP Prof. Dr. R. D. Kandou Manado periode November 2017-Desember 2018 dilakukan berdasarkan status rekam medik. Dari 32 sampel yang diteliti, tidak ditemukan adanya pasien yang meninggal. Hal ini bertolak belakang dengan penelitian yang dilakukan oleh Panula et $\mathrm{al}^{14}$ dan Haentjens et $\mathrm{al}^{22}$ yang menyatakan bahwa patah tulang pinggul juga dapat menyebabkan kematian, dan tingkat kematian pada pasien manula yang mengalami patah tulang 
pinggul berkisar antara 14\%-36\% dalam setahun setelah cedera.

\section{SIMPULAN}

Pada penelitian terhadap pasien manula dengan hip replacement di RSUP Prof. Dr. R. D. Kandou Manado periode November 2017 - Desember 2018 didapatkan bahwa waktu tunggu operasi (delayed time) dapat memicu peningkatan risiko komplikasi pasca operasi, namun tidak terdapat dampak antara waktu tunggu operasi terhadap peningkatan angka mortalitas pada semua pasien dalam periode ini.

\section{Konflik Kepentingan}

Penulis menyatakan tidak terdapat konflik kepentingan dalam studi ini.

\section{DAFTAR PUSTAKA}

1. Sjamsuhidajat R, de Jong W. Buku Ajar Ilmu Bedah (3rd ed). Jakarta: EGC, 2014; p. 1066.

2. Mariorenzi MC. Ferri's Clinical Advisor. 2019, p. 681.

3. Langley J, Samaranayaka A, Davie G, Campbell AJ. Age, cohort and period effects on hip fracture incidence: analysis and predictions from New Zealand data 1974-2007; Osteoporos Int. 2010;22:105-11.

4. Maalouf G, Bachour F, Hlais S, Maalouf NM, Yazbeck P, Yaghi Y, et al. Epidemiology of hip fractures in Lebanon: A nationwide survey. Orthopaedics \& Traumatology: Surgery \& Research. 2013;99:675-680.

5. Lewiecki ME, Wright NC, Curtis JR, Siris E, Gagel RF, Saag K, et al. Hip fracture trends in the United States, 2002 to 2015. Osteoporos Int. 2017;22:465.

6. Ettinger B, Black D, Dawson-Hughes B, Pressman AR, Melton LJ. Updated fracture incidence rates for the US version of FRAX. Osteoporos Int. 2010;21:25-33.

7. Abraham B, Vestergaard P. Declining incidence of hip fractures and the extent of use of anti-osteoporotic therapy in Denmark 1997-2006. Osteoporos Int. 2010;21:373-80.

8. Karacic TP, Kopjar B. Hip fracture incidence in Croatia in patients aged 65 years and more. Lijec Vjesn. 2009;131:913.

9. Leal J, Gray AM, Prieto-Alhambra D, Cooper C, Javaid MK, Judge A, et al. Impact of hip fracture on hospital care costs: a population-based study. Osteoporos Int. 2015;27:549-58.

10. Kanis JA, Oden A, McCloskey EV, Johansson H, Wahl DA, Cooper C, et al. A systematic review of hip fracture incidence and probability of fracture worldwide. Osteoporos Int. 2012;23:2239-56.

11. Marques A, Lourenco O, da Silva JAP. The burden of osteoporotic hip fractures in Portugal: costs, health related quality of live and morality. Osteoporos Int. 26:2623-2630. 2015.

12. Tan LT, Wong SJ, Kwek EB. Inpatient cost for hip fracture patients managed with an orthogeriatric care model in Singapore. Smedj 58:p139-144. 2017.

13. Lyons AR. Clinical outcomes and treatment of hip fractures. Am J Med. 1997; 103:51S-64S.

14. Panula J, Pihlajamaki H, Mattila VM, Jaatinen P, Vahlberg T, Aarnio P, et al. Mortality and cause of death in hip fracture patients aged 65 or older - a population - based study. BMC Musculoskeletal Disorders. 2011;12: 105.

15. Lizaur-Utrilla A, Martinez-Mendez D, Collados-Maestre I, Miralles-Munoz FA, Marco-Gomez L, Lopez-Prats FA. Early surgery within 2 days for hip fracture is not reliable as healthcare quality indicator. Injury. 2016; 47:1530-5.

16. Schnell S, Friedman SM, Mendelson DA, Bingham KW, Kates SL. The 1-year mortality of patients treated in a hip fracture program for elders. Geriatr Orthop Surg Rehabil . 2010;1:6-14.

17. Zuckerman JD. Hip fracture. N Engl J Med. 1996;334:1519-25.

18. Morrinson RS, Chassin MR, Siu AL. The medical consultant's role in caring for patients with hip fracture. Ann Intern Med. 1998;128:1010-20.

19. Parker M, Johansen A. Hip fracture. BMJ. 2006;333:27-30.

20. Haleem S, Lutchman L, Mayahi R., Grice JE, Parker MJ. Mortality following hip fracture: trends and geographical 
variations over the last 40 years. Injury. 2008;39:1157-63.

21. Tolppanen A-M, Taipale H, Tanskanen A, Tiihonen J, Hartikainen S. Comparison of predictors of hip fracture and mortality after hip fracture in community-dwellers with and without Alzheimer's disease - exposure matched cohort study. BMC Geriatr. 2016;16:204.

22. Haentjens P, Magaziner J, Colon-Emeric CS, Vanderschueren D, Milisen K, Velkeniers B. et al. Meta-analysis: excess mortality after hip fracture among older women and men. Ann Intern Med. 2010;152:380-90.

23. Silvia ARV, Juchno P, Marcui M, Wronsk A. Eurostat Demography Report Short Analytical Web Note 3/2015. 2015.

24. Xu J, Murphy S, Kenneth D, Kochanek M, Arias E. Mortality in the United States, 2015. NCHS Data Brief. 2016;267.

25. OECD. Health at a Glance 2015. OECD Indicators, 2015;1-220.

26. Carpintero P. Complications of hip fractures: A review. WJO. 2014;5: 402-11.

27. Roberts KC, Brox WT, Jevsevar DS, Sevarino K. Management of hip fractures in the elderly. J Am Acad Orthop Surg. 2015;23:131-7.

28. National Guideline C. American Academy of Orthophedic Suegeons clinical practice guideline on management of hip fractures in the elderly. 2014.

29. NICE. Hip fracture: management, Clinical guideline [CG124]. 2014.

30. Bhandari M, Swiontkowski M. Management of acute hip fracture. $\mathrm{N}$ Engl $\mathrm{J}$ Med. 2017;377:2053-62.

31. Orosz GM, Magaziner J, Hannan EL, Morrison RS, Koval K, Gilbert M. et al. Association of timing of surgery for hip fracture and patient outcomes. JAMA. 2004;291:1728-43.

32. Parker MJ, Pryor GA. The timing of surgery for proximal femoral fractures. J Bone Joint Surg Br. 1992;74:203-5.

33. Smektala R, Endres HG, Dasch B, Maier C, Trampisch HJ, Bonnaire F. et al. The effect of time-to-surgery on outcome in elderly patients with proximal femoral fractures. BMC Musculoskeletal Disorders. 2008;9:387-9.

34. American Academy of Orthopaedic Surgeons, Hip Fracture. 2009. Available from: http://orthoinfo.aaos. org/topic.cfm?topic=A00392.

35. Kosnayani AS. Asupan kalsium, aktivitas fisik, paritas \& IMT dengan kepadatan tulang pascamenopause [Tesis]. Semarang: Universitas Dipopnegoro; 2007.

36. Nurwahyuni D, Wirawanni. Hubungan antara asupan kalsium, aktivitas fisik dan frekuensi konsumsi teh dengan kepadatan tulang pada wanita pasca menopause [Artikel penelitian]. Semarang: Universitas Diponegoro; 2009.

37. Fatmah. Osteoporosis dan faktor resikonya pada lansia etnis Jawa. Media Medika Indonesiana. 2008;43(2)1-13. 